\title{
A STUDY TO COMPARE THE EFFECTIVENESS OF SINGLE TASK TRAINING VS DUAL TASK TRAINING ON BALANCE IN PARKINSONS PATIENTS
}

Albin Jerome $^{\# 1}$, C.V.John Franklin
\#2,SankaraKumaran Pandian
\#1, Lecturer, School of Physiotherapy, FAHP, AIMST University, Bedong,
+601124145647
\#2 Principal, Rovers College of Physiotherapy, Perambalur, Tamil Nadu, India,
+919787938044
\#3 Lecturer, School of Physiotherapy, FAHP, AIMST University, Bedong,
+601126731934

\section{ABSTRACT}

BACKROUND: Parkinson disease is a very common neurodegenerative disease that affects more than 2 percent of the population older than 65 years of age. Many persons with Parkinson disease report impaired balance and falls.Patients with Parkinson disease are frequently referred for physical therapy to improve balance control and reduce the risk of falling. The majority of individuals with Parkinson disease will develop problems with postural instability and falls. Traditionally people with Parkinson's disease were advised to avoid performing dual task while walking AIM: Since both single task and dual task condition have been used for Parkinson's patient, the purpose of this study is to find out an effective task training to improve balance in Parkinson's patients METHODOLOGY: An experimental study was conducted on 20 clinically diagnosed idiopathic (stage 3 according to Hoehn\&Yahr score)Parkinson's patient with age of 50-80 years who did not experience motor response fluctuations with mini mental state examination score greater than 24 were included in the study.Patients with uncontrolled Diabetes mellitus, with diagnosed visual and auditory impairment, with diagnosed visual and auditory impairment, unstable cardiorespiratory condition were excluded from the study. PROCEDURE:Written consent regarding their voluntary participation in the study was taken. Mini mental state examination and Berg balance scale was taken pre training for each patient.Then the patients were randomly divided into two groups. Age matched samples were taken in both the groups Group A were asked to perform single task activities and conventional PT treatment, while Group B performed dual task activities and conventional PT treatment.RESULTS: The mean difference of group $A=6 \pm 1.155$ and that of group $B=4.3 \pm 0.8233$ with ' $t$ ' value $=3.791$ Mean of Group A shows more significant values with $p \leq 0.001$ as compared to Group B, suggesting Single task training is more effective in balance training in Parkinson's patients. CONCLUSION:The study result indicates that both the group showed beneficial effect on balance in patients with Parkinson's disease but there was additional effect found in Group A trained on Single task training. Thus Single task training is an effective task training to improve balance in Parkinson's patients

Key words:Parkinson Disease, Single task, Dual task, Balance

Corresponding Author: Mr.Albin Jerome 


\section{INTRODUCTION}

Parkinson's disease (PD) is a chronic, progressive, neurologic disorder characterized pathologically by the degeneration of dopaminergic neurons in the substantianigra and the subsequent depletion of striatal dopamine. The disease is named for the English physician James Parkinson who first described it in An Essay on the Shaking Palsy in 1817. in his words, it is characterized by "involuntary trmendulous motion with lessened muscular power,in parts not in action when supported; with a propensity to bend the trunk forwaed and to pass from a walking to running pace, the sense and intellect being uninjured." Parkinsons Disease is a progressive neurological illness with a strong age associated risk.Hallmark clinical motor features instability.As no definitive diagnostic test exists for Parkinsons Disease, the presence of 2 clinical features, with at least 1 being tremor at rest or bradykinesia, is needed to confirm a diagnosis of Parkinsons Disease.

Parkinson disease is a very common neurodegenerative disease that affects more than 2 percent of the population older than 65 years of age. Average age of Parkinsons Disease is approximately 50 to 60 years.

Strategies for enhancing balance among older adults with Parkinsons Disease are needed, because in the absence of regular physical activity, balance and muscle

strength deteriorate in persons with Parkinsons Disease. Single task training involves practicing functional task requiring balance (eg standing, walking and transfers) in isolation.

Difficulty performing two tasks at the same time is a frequent and debilitating problem in idiopathic Parkinson disease. Dual task interference in Parkinsons Disease affects both movement and cognition is accentuated when tasks are part of a long or complex sequence. Typically, patients complain of "freezing" episodes when they are trying to walk at the same time as performing concurrent tasks such as talking, carrying a tray of drinks, or retrieving coins from their pocket. When their attention focuses on the second task, their footsteps become short and slow, the ground clearance reduces, and movement can cease

Traditionally people with Parkinson's disease were advised to avoid performing dual task while walking. Rehabilitation program advice the need to train walking under single task conditions to improve gait and reduce risk of falls Recent researches have shown that as dual tasks are an integral part of daily life of any person specific training should be emphasized in the rehabilitation process. There are also findings that avoiding dual task during walking or retraining in people with mild to moderate Parkinsons Disease may not be necessary.

Since training under both single task and dual task condition have been reported therefore, the purpose of this study is to compare 2 approaches to training balance- single task and dual task in Parkinson's patients.

Since both single task and dual task condition have been used for Parkinson's patient, the purpose of this study is to find out an effective task training to improve balance in Parkinson's patients

\section{MATERIALS AND METHODS}

An experimental study was conducted on 20 clinically diagnosed idiopathic (stage 3 according to Hoehn\&Yahr score).Parkinson's patient of both genders with age of 50-80 years who did not experience motor response fluctuations with mini mental state examination score greater than 24 were included in the study. Patients with uncontrolled Diabetes mellitus, with diagnosed visual and auditory impairment, Unstable cardiorespiratory condition which may affect the training procedure and having history of any other neurological disease and musculoskeletal impairment that could account for possible balance 
impairment like CVA,TIA, vestibular disorder, joint replacement, fractures etc. were excluded from the study

Patients who fulfilled the inclusion criteria were taken up for the study purpose. Written consent regarding their voluntary participation in the study was taken. The purpose of the study and procedure was explained to the subject.Mini mental state examination was taken pre training for each patient. Pre-training scores on Berg's balance scale was recorded. Then the patients were randomly divided into two groups. Age matched samples will be taken in both the groups

Group A performed single task activities+ conventional PT treatment. Group B performed dual task activities+ conventional PT treatment. Single task training includes tandem standing with both eyes open and eyes closed on a stable surface, tandem standing with both eyes open and eyes closed on a unstable surface, tandem walking with narrow base of support on a stable surface and tandem walking with narrow base of support on a unstable surface.Dual task training includes Tandem walking on a stable surface and N-back test in which patients were asked to recite numbers, days or months backwards. Second dual task was to Walk on an unstable surface, Walking Backwards on an unstable surface and Naming things or words like as types of flowers, states, fruits. Third dual task was walking sideways on a stable surface and tell a story like what they did in morning, what they did on their vacation and so on.Training for both groups will be given for period of 4 weeks, three sessions per week. Exercises were terminated if patient feels fatigue or on demand. Appropriate rest pause between each exercise was given. After 4 weeks of training, each patient will be reassessed for Berg balance scale.

\section{STATISTICAL ANALYSIS}

In this study 20 subjects was included to compare the effect of single task versus dual task training on balance in Parkinson's patients. The statistical test used for the analysis of the result was paired t-test and unpaired t-test. $T$ distribution tests are used to find significant difference between scores of pre and posttest in each group and between groups. Paired t test was used to compare the pre and post treatment. Unpaired t-test used to compare data between the groups

\section{RESULTS}

1.By applying paired t-test for group A :

The mean value of berg balance scale score pre training was $42.8 \pm 4.05$ which showed significant improvement in post treatment mean value of BBS as $48.8 \pm 3.19$ with $\mathrm{t}$ value $=-16.432$ and $\mathrm{p}<0.001$

TABLE 1:COMPARISON OF PRE AND POST TREATMENT BERG BALANCE

SCALE SCORE OF GROUP A

\begin{tabular}{|c|c|c|}
\hline & Mean & StdDev \\
\hline Pre-treatment & 42.8 & 4.05 \\
\hline Post treatment & 48.8 & 3.19 \\
\hline Difference & -6.0 & 1.155 \\
\hline
\end{tabular}

2. By applying paired t-test for group B: 
The mean value of berg balance scale score pre training was $46.5 \pm 2.369$ and following intervention it was $50.8 \pm 2.15$ with $t$ value $=-16.517$ and $p<0.001$

TABLE 2: COMPARISON OF PRE AND POST TREATMENT BERG BALANCE SCALE SCORE OF GROUP B

\begin{tabular}{|c|c|c|}
\hline & Mean & StdDev \\
\hline Pre-treatment & 46.5 & 2.369 \\
\hline Post treatment & 50.8 & 2.15 \\
\hline Difference & -4.3 & 0.8233 \\
\hline
\end{tabular}

3.By applying unpaired t-test for comparison between Group A and Group B:

The mean difference of group $\mathrm{A}=6 \pm 1.155$ and that of group $\mathrm{B}=4.3 \pm 0.8233$ with ' $\mathrm{t}$ ' value $=3.791$ as shown in Table 3. Mean of Group A shows more significant values with $\mathrm{p} \leq 0.001$ as compared to Group B, suggesting Single task training is more effective in balance training in Parkinson's patients.

TABLE 3 :COMPARISON OF MEAN DIFFERENCE BERG BALANCE SCORE OF GROUP A AND GROUP B

\begin{tabular}{|c|c|c|}
\hline Group & Mean Difference & StdDev \\
\hline Group A & 6 & 1.155 \\
\hline Group B & 4.3 & 0.8233 \\
\hline Difference & 1.7 & 0.4485 \\
\hline
\end{tabular}

4. As per Table 4, age distribution showed more number of Parkinson's patient from age group of 50-55 and 66-70 in both the groups with 3 patients in each age group. The mean age in both groups was 62 year of age.

TABLE 4 : DEMOGRAPHIC REPRESENTATION OF AGE IN GROUP AND

$$
\text { GROUP B }
$$

\begin{tabular}{|c|c|c|}
\hline AGE GROUPS & GROUP A & GROUP B \\
\hline $\mathbf{5 0 - 5 5}$ & 3 & 3 \\
\hline $\mathbf{5 6 - 6 0}$ & 1 & 2 \\
\hline $\mathbf{6 1 - 6 5}$ & 2 & 3 \\
\hline $\mathbf{6 6 - 7 0}$ & 1 & 1 \\
\hline $\mathbf{7 1 - 7 5}$ & 0 & 0 \\
\hline $\mathbf{7 6 - 8 0}$ & & \\
\hline
\end{tabular}


5. Table 5 showsinferential statistics for age- matching for both the groups. By applying unpaired t-test for comparison between Group A and Group B.The mean difference of group $\mathrm{A}=61.9 \pm 7.964$ and that of group $\mathrm{B}=62.0 \pm 7.717$ with ' $\mathrm{t}$ ' value $=-0.029$ .There is no significant difference in the mean value of age between both the groups with $\mathrm{p}<0.001$. This suggest that age matching is done in the study.

TABLE 5:INFERENTIAL STATISTICS FOR AGE- MATCHING FOR BOTH THE GROUPS

\begin{tabular}{|l|c|c|}
\hline Group & Mean & StdDev \\
\hline Group A & 61.9 & 7.964 \\
\hline Group B & 62.0 & 7.717 \\
\hline Difference & -0.1 & 3.507 \\
\hline
\end{tabular}

6. Table 6 shows the range of years of affection of disease between Group A and Group B.

The range of duration of the disease for both the groups was between 8-13 years and the mean was 10 years.

TABLE 6 :DEMOGRAPHIC REPRESENTATION OF DURATION OF THE DISEASE IN GROUP A AND GROUP B

\begin{tabular}{|c|c|c|c|}
\hline YEARS & GROUP A & GROUP B & TOTAL \\
\hline $\mathbf{6 - 7}$ & 1 & 0 & 1 \\
\hline $\mathbf{8 - 9}$ & 4 & 4 & 8 \\
\hline $\mathbf{1 0 - 1 1}$ & 4 & 3 & 7 \\
\hline $\mathbf{1 2 - 1 3}$ & 1 & 3 & 4 \\
\hline
\end{tabular}

\section{CONCLUSION}

This study investigated the relative effectiveness of the single task training compared with dual task training physical on balance. Our finding showed that patient treated with sing task balance training and those treated with dual task balance training both clinically and statistically showed significant improvement, but the improvement was greater in Group A i.e. with single task training. Therefore we can say single task training is more effective than dual task training to improve balance in patients with Parkinson's disease.

This improvement in performance as a function of training clearly reflects learning. Learning occurred regardless of the individual executing the simple or dual task. Therefore, although the improvement with dual task training was less comparatively, it was also amenable to learning, with improvement in performance. ${ }^{4}$ Recent work with animal models of Parkinsons Disease, stroke, and spinal cord injury indicates that rehabilitative training can stimulate a number of plasticity-related events in the brain and the spinal cord, including neuronal outgrowth, neurotrophic factor expression, synaptogenesis, and even neurogenesis. Our results demonstrated that the ability to perform the dual task is not totally lost in patients 
with Parkinson's disease. With proper training, they can execute some dual tasks correctly.P.Soliveri et al suggest that patients with Parkinson's disease are capable of schema learning but require more practice than control subjects to achieve comparable levels of performance. This may be a reflection of the fundamental motor dysfunction of the disease rather than a specific learning deficit.

Although there was improvement with dual task training on berg balance score but the improvement was not equal to as seen in single task training. There are 2 explanations. First, central processing resources become depleted because of degeneration of neurones of the substantianigra pars compacta in the brain stem and consequent dopamine insufficiency. Because dopamine is one of the main neurotransmitters used by the basal ganglia in the control of well-learned, sequential actions, the ability to perform these goal-directed tasks without undue attention is compromised. Second, there is some evidence to suggest that the basal ganglia-frontal cortex-basal ganglia feedback loops play a critical role in regulating movement automaticity. According to Iansek and coworkerswhen two tasks are performed at the same time one usually runs at a subconscious level through the basal ganglia while the person attends to the other, which is controlled by the frontal cortex. If the basal ganglia are defective then the automatic task becomes slow, reduced in amplitude, or ceases altogether.

In Parkinsons Disease the neurotransmitter imbalance that arises in the basal ganglia as a result of a reduction in dopaminergic neurons disrupts the motor functions of the basal ganglia. It can be suggested that as a compensation patients rely more heavily on frontal cortical regions and "on-line"' visual, proprioceptive, and auditory input to consciously control and guide movements, and bypass the defective basal ganglia.The shortcoming of this type of compensation is that it is resource-demanding and leaves patients with little in reserve when they need to perform an additional task at the same time as they are attending to the primary task.

Teixeira NB and Alouche SR mentioned that patients with Parkinson's disease can generate normal motor patterns when they focus their attention on performance, that is, when they think on the execution of movements. This way they activate the intact pre-motor cortex area and avoid relying on the impaired circuitry of the basal nuclei to and assist in the production of movements. In dual task situations, the use of these cortical resources to execute motor tasks can restrict performance in both tasks.

A number of models have been proposed to explain observed dual tasking decrement (1) the capacity- or resource-sharing model, (2) the bottleneck model 3) the cross-talk model. 1. Capacity-sharing models are based on the assumption that attention resources are limited. Therefore, when people perform 2 tasks simultaneously, attention must be divided between the tasks. How attention is divided between the 2 tasks relies on several factors, including task complexity, familiarity, and importance. Dual task interference will occur only if the available resource capacity is exceeded, resulting in a decline in performance on one or both of the tasks. The capacity-sharing model allows for the concept of parallel processing (as opposed to serial processing) of information.

1.The bottleneck and cross-talk models assume that dual task interference is affected by the type of tasks performed simultaneously, rather than the amount of attention needed to sustain performance.

2. According to the bottleneck model, similar tasks performed concurrently cause "bottleneck" interference because they compete for the use of the same pathways.

3. In contrast, cross-talk models assume that task similarity reduces dual task interference, because the use of the same pathway increases the efficiency of processing by using less attentional resource capacity. 
The results of our study lend support to the capacity-sharing model of dual task interference. For elderly people with Parkinsons Disease, a large proportion of the attentional capacity appeared to be directed toward the cognitive tasks at the expense of balance performance. The bottleneck model the cross-talk model are excluded because study included training with different type of simultaneous task ie cognitive task as secondary task and not the motor task as secondary one. Nevertheless, to support this models further investigation is required to systematically evaluate the effects of type of concurrent task - motor or cognitive on balance in subjects with Parkinsons Disease. Future investigations should also consider the level of difficulty of primary and secondary tasks.

The mean age of onset for Parkinsons Disease is between 58-62 years, with majority of cases having their onset between the ages of 50 and 79, the motor as well as non motor symptoms of PARKINSONS DISEASE which include depression, cognition etc. intensify as the disease progresses, and result in a considerable burden of illness associated with Parkinson's disease. In accordance with these findings, the present study also demonstrated that the entire sample population was within an age group range of 50-80 years .

Once balance deteriorates in Parkinsons Disease, it is important to have a quantifiable tool that health care professionals can use to monitor these changes. The Berg Balance Scale (BBS) has been the main instrument used to identify and to evaluate balance impairment in different populations, although this scale was originally designed to assess the risk of falling in elderly patients. Psychometric properties of this scale have been examined by various researchers. These studies showed strong internal consistency and inter- and intra-rater reliability in neurological diseases, such as stroke and Parkinsons Disease. Nova et al. demonstrated that the BSS had enough sensitivity to detect balance changes during on-off fluctuation in Parkinsons Disease patients on levodopa therapy.

BBS scores showed significant correlations with Parkinsons Disease-specific instruments that measure motor functioning, stage of disease and daily living capacity. These researchers proposed that the BBS may be used for screening and ongoing assessment for ParkinsonsDisease.The Berg Balance Scale therefore was chosen as the assessment tool in this experiment because we believe it is the measures of balance and mobility that relate to real-life meaningful activities such as transfers, stair climbing. This measure is also widely used, easy to administer, \& yield measurements that have known reliability and validity.

Cognition has an role in balance, so to assess cognition in this study mini mental scale has been used as a tool to included patient with normal cognition level i.e. score of 24 or above. Below 24/30 score the person is consider to have less cognitive function. Sebestine A. Borges, OnaVyas in 2001 did study to determine the effect of cognitive and perceptual deficits on sitting and standing balance following stroke. He concluded cognitive and perceptual deficits following stroke, influence balance. Standing balance places more demands on the subject's attention and cognitive abilities. There is a direct impact on balance abilities themselves; these cognitive problems impede motor learning processes which are crucial for the relearning of balance skills. Therefore, screening of cognitive deficits can provide valuable information for determining treatment strategies for difficulties in balance.

The patients in both the groups were relatively homogeneous; all were stage 3 on the Hoehn and Yahr scale and did not have motor response fluctuations. Non fluctuating patients with relatively moderate disease progression were chosen to minimize the confounding effects of medication wear-off. In patients with motor response fluctuations, one has to carefully control for peaks and troughs in performance due to the medication effect. Given the duration of the study, we tried to alleviate this problem by studying patients who did not have motor response fluctuations. Another reason for choosing such patients is that patients in Hoehn and Yahr stages 4-5 might have great difficulties with walking and balancing (especially in stage 5) and training could potentially be unsafe. 


\section{REFERENCE}

[1] MAO-B inhibitors for the treatment of Parkinson's disease. MovDisord. 2002;17(suppl 4):S38-S44

[2] Zijlstra A Et al.Do dual tasks have an added value over single tasks for balance assessment in fall prevention programs? A mini-review ,Gerontology. 2008;54(1):40-9. Epub 2008 May 7.

[3] Hetherington V, Jones D, Nieuwboer A, Willems AM, Kwakkel G, Van Wegen Attending to the task: interference effects of functional tasks on walking in Parkinson's disease and the roles of cognition, depression, fatigue, and balance, Arch Phys Med Rehabil 2004 Oct; 85(10):1578-85.

[4] Teixeira NB; AloucheSR, Dual task performance in Parkinson's disease , Rev. bras. fisioter. vol.11 no.2 São Carlos Mar./Apr. 2007.

[5] Silsupadol Patima ; Ka Chun Sui; Shumway-Cook Anne ,Training of balance under single and dual task conditions in older adults wiyh balance impairment ,Physical Therapy.Vol 86.Number 2.February2006.

[6] Lynn Rochester, ,AliceNieuwboer , Katherine Baker et al, Walking speed during single and dual tasks in Parkinson's disease: Which characteristics are important? 2008 Movement Disorder Society, Accepted: 16 June 2008

[7] Brown LA, Shumway-Cook A, Woollacott MH. Attentional demands and postural recovery: the effects of aging. J Gerontol A BiolSci 1999;54:M165-M171.

[8] Physical rehabilitation-fifth edition-Susan O'Sullivan chapter9 pg 857-858.

[9] Lundin-Olsson L, Nyberg L, Gustafson Y. "Stops walking when talking" as a predictor of falls in elderly people [letter]. Lancet.1997;349:617.

[10] T $\mathrm{Wu}, \mathrm{M}$ Hallett . Neural correlates of dual task performance in patients with Parkinson's disease. Journal of Neurology, Neurosurgery, and Psychiatry 2008;79:760-766.

[11] Wolf B, Feys H, de Weerdt, Effect of a physical therapeutic intervention for balance problems in the elderly: a single-blind, randomized, controlled multicentre trial. ClinRehabil. 2001;15: 624-636.

[12] Pamela Ching Kwan, People with Parkinsonism should avoid dual task activities while walking: myth or reality.10187/4862 (2009)

[13] Rosin FM, Galera C. Effect of training on ability of dual task on coordination, Braz Med Bio Res;32 (10):1249-61.

[14] Christopher G. Goetz. Movement Disorder Society Task Force report on the Hoehn and Yahr staging scale: status and recommendations. MovDisord. 2004 Sep;19(9):1020-8

[15] MMSE, M. F. Folstein, S. E. Folstein, and P. Modified From: Rush J, et al: Psychiatric Measures, APA, Washington DC, 2000.

[16] Tombaugh TN, McIntyre NJ. The mini-mental state examination: a comprehensive review. J Am Geriatr Soc.1992;40(9):922-935.

[17] Geraldine L. Pellecchia : Dual-Task Training Reduces Impact of Cognitive Task on Postural Sway. Journal of Motor Behavior Volume 37, Number 3 / May 2005 $239-246$

[18] Colleen G Canning, Cathie Sherrington : Exercise therapy for prevention of falls in people with Parkinson's disease: A protocol for a randomised controlled trial and economic evaluation. BMC Neurology 2009, 9:4. 
[19] Laurent Bensoussan, MD, Jean-Michel Viton, MD, PhD, Marco Schieppati, MD, HervéCollado, MD, Changes in Postural Control in Hemiplegic Patients After Stroke Performing a Dual Task. Arch Phys Med Rehabil 2007;88:1009-15.

[20] Aunrey Bowen, Rachel Wenman, Jane Mickelborough, Elizabeth Hill: Dual Task effect of talking while walking on velocity and balance following stroke, Age and Aging 2001;30;319-23.

[21] Paula L. Scalzo, Isabella C. Nova, Mônica R. Perracini3, Daniel R.C. Sacramento, Francisco Cardoso, Henrique B. Ferraz, Antonio Lúcio; Validation of the brazilian version of the berg balance scale for patients with parkinson's disease , ArqNeuropsiquiatr 2009; 67(3-B):831-835

[22] P. Santens, P. Boon, D. Van Roost and J. Caemaert ; The pathophysiology of motor symptoms in Parkinson's disease ; Acta neurol. belg., 2003, 103, 129-134

[23] Jonathon Edward Bruce Doan; Movement deficits for Parkinson's disease patients in select functional behaviours: context opposes sequence and consequence; Canadian Centre for Behavioural Neuroscience and Department of Kinesiology and Physical Education University of Lethbridge, Lethbridge, Alberta, Canada 2006

[24] Patricia M. Davies. Steps to follow: The comprehensive treatment of patients with hemiplegia, Chapter No.2, Second Edition, New Delhi, JaypeeBrothers Medical Publishers (P) Ltd., 2003, Page No.235-276.

[25] Frances E Huxham, Patricia A Goldie and Aftab E Patla ; Theoretical considerations in balance assessment; Australian Journal of Physiotherapy 47: 89$100]$

[26] P Soliveri, R G Brown, M Jahanshahi, C D Marsden. Effect of practice on performance of a skilled motor task in patients with Parkinson's disease. journalof Neurology, Neurosurgery, and Psychiatry 1992;55:454-460

[27] Leland E. Dibble, Odessa Addison, and Evan Papa ;The Effects of Exercise on Balance in Persons with Parkinson's Disease: A Systematic Review Across the Disability Spectrum, JNPT • Volume 33, March 2009.

[28] Marjm'e H Woollacott, Pei-Fang Tang.Balance Control During Walking in the Older Adult:Research and Its Implications Physical Therapy. Volume 77. Number 6 . June 1997

[29] Jaqueline M. Bond, Meg Morris,; Goal-Directed Secondary Motor Tasks: Their Effects on Gait in Subjects With Parkinson Disease; Arch Phys Med RehabilVol 81, January 2000.

[30] Haggard P, Cockbum J, Cock J, Fordham C, Wade D. Interference between gait and cognitive task in a rehabilitating neurological population. J NeurolNeurosurg Psychiatry. 2000;69:479-86.

[31] Mulder T, Zijlstra W, Geurts A. Assessment of motor recovery and decline. Gait and Posture. 2002;16:198-210.

[32] Cook J, Fordham C, Cockburn J, Haggard P. Who knows best? Awareness of divided attention difficulty in a neurological rehabilitation setting. Brain Inj. 2003;17(7):561-74.

[33] Morris ME, Iansek R, Matyas TA, Summers JJ. Stride length regulation in Parkinson's disease: normalization strategies and underlying mechanisms. Brain 1996;119:551-68.

[34] Morris ME, Bruce M, Smithson F, Dodd K, Bond J, Huxham F. Physiotherapy strategies for people with Parkinson's disease. In: Morris ME, Iansek R, editors. Parkinson's disease: a team approach. Blackburn, Australia: BuscombeVicprint; 1997. p.27-64. 
[35] Iansek R, Bradshaw JL, Phillips JG, Cunnington R, Morris ME. Interaction of the basal ganglia and supplementary motor area in the elaboration of movement. In: Glendross D, Piek J, editors. Motor control and sensorimotor integration. Amsterdam: Elsevier Science; 1995. p. 49-60.

[36] Karen McCulloch, Attention and Dual-Task Conditions: Physical Therapy Implications for Individuals With Acquired Brain Injury JNPT • Volume 31, Sept 2007

[37] Raymond D Adams, Maurice Victor; Principles of neurology; Sixth edition;1068.

[39] Merrill Landersa, et.al ,An external focus of attention attenuates balance impairment in patients with Parkinson's disease who have a fall history; Physiotherapy.Volume 91, Issue 3, Pages 152-158 (September 2005)

[40] Richard Camicioli, MD, Diane Howieson, PhD, Suzanne Lehman, BS and Jeffrey Kaye, MD; Talking while walking ; The effect of a dual task in aging and Alzheimer's disease ; Neurology April 1, 1997 vol. 48 no. 4 955-958

[41] Matinolli, M. Korpelainen, J. T. Korpelainen, R.; Sotaniemi, K. A.; Matinolli, V.M.; Myllylä, V. Mobility and balance in Parkinson's disease: a population-based study ; European Journal of Neurology, Volume 16, Number 1

[42] Ruthgeiger, Hicks, Allen, Keefe . Balance \& mobility following stroke: effect of physiotherapy intervention with \&without biofeedback training. Physical therapy 2001; 81:995-1005

[43] Sebestina a. borges, Ona a. vyas. a study addressing the impact of cognitive and perceptual deficits on sitting and standing balance following cerebrovascular accident. The Indian Journal of Occupational Therapy : Vol. XXXIII : No. 1, AprilJuly 2001

[44] Karen H Karlsen et.al. Health related quality of life in Parkinson's disease: a prospective longitudinal study. J NeurolNeurosurg Psychiatry 2000;69:584-589

[45] S. J. Palmer,al. Eigenraam,c t. Hoque, r. G. Mccaig, a. Troiano and m. J. Mckeown; levodopa-sensitive, dynamic changes in effective connectivity during simultaneous movements in parkinson's disease; neuroscience 158 (2009) 693704.

[46] Robyn Galletly and Sandra G Brauer, Does the type of concurrent task affect preferred and cued gait in people with Parkinson's disease? Australian Journal of Physiotherapy 2005 Vol. 51175.

[47] GalitYogev,Nir Gila; ChavaPeretz; ShmuelSpringer,Ely S. Simon and Jeffrey M. Hausdor; Dual tasking, gait rhythmicity, and Parkinson's disease:Which aspects of gait are attention demanding? European Journal of Neuroscience, Vol. 22, pp. 1248-1256, 2005 .

[48] Tao Wu and Mark Hallett ; A functional MRI study of automatic movements in patients with Parkinson's disease; Brain (2005), 128, 2250-2259.

[49] Qutubuddin AA, Pegg PO, Cifu DX, Brown R, McNamee S, Carne W. Validating the Berg Balance Scale for patients with Parkinson's disease: a key to rehabilitation evaluation. Arch Phys Med Rehabil 2005;86:789-92.

[50] Dawes H, Cockburn J, Roach NK, et al. The effect of a perceptual cognitive task on exercise performance: the dual-task condition after brain injury. ClinRehabil. 2003;17:535-539.

[51] Mark A. Hirsch, Tonya Toole, Charles G. Maitland, MD, Robert A. Rider, ;The Effects of Balance Training and High-Intensity resistancetraining on Persons With Idiopathic Parkinson's Disease; Arch Phys Med RehabilVol 84, August 2003. 
[52] O'Shea S, Morris M and Iansek R (2002): Dual task interference during gait in people with Parkinson's disease: Effects of motor versus cognitive secondary tasks. Physical Therapy 82: 888-897.

[53] Christopher G. Goetz et.al. Movement Disorder Society Task Force report on the Hoehn and Yahr staging scale: status and recommendations. Movement disorder, Vol. 19, No. 9, 2004, pp. 1020-1028

[54] Christopher G. Goetz et.al. Movement Disorder Society Task Force report on the Hoehn and Yahr staging scale: status and recommendations. Movement disorder, Vol. 19, No. 9, 2004, pp. 1020-1028

[55] Joe Nocera et.al. Relationship between balance and cognition in Parkinson's disease. 2008

[56] Darcy A Umphred; Neurological Rehabilitation $5^{\text {th }}$ edition. USA.2007 Mosby Elsevier:

[57] Ted J Stevenson. Detecting change in patients with stroke using the Berg Balance Scale. Australian Journal of Physiotherapy 2001,vol 47: 29-38 